\title{
The real-life experience with cardiovascular complications in the first dose of fingolimod for multiple sclerosis
}

\section{A experiência da vida real com complicações cardiovasculares na primeira dose de fingolimode}

Yara Dadalti Fragoso ${ }^{1}$, Christian Cardoso Arruda ${ }^{2}$. Walter Oleschko Arruda ${ }^{3}$, Joseph Bruno Bidin Brooks ${ }^{1}$, Alfredo Damasceno ${ }^{4}$, Carlos Augusto de Albuquerque Damasceno ${ }^{5}$, Alessandro Finkelsztejn ${ }^{6}$, Juliana Finkelsztejn', Paulo Diniz da Gama7, Maria Cristina Brandão Giacomo ${ }^{8}$, Sidney Gomes ${ }^{9}$, Marcus Vinicius Magno Goncalves ${ }^{10}$, Andre Palma da Cunha Matta ${ }^{11}$, Marilia Manprim de Morais ${ }^{12}$, Enedina Maria Lobato de Oliveira ${ }^{12}$, Yuna Ribeiro ${ }^{13}$. Henry Koiti Sato ${ }^{14}$, Carlos Bernardo Tauil ${ }^{13}$

\begin{abstract}
Fingolimod is a new and efficient treatment for multiple sclerosis (MS). The drug administration requires special attention to the first dose, since cardiovascular adverse events can be observed during the initial six hours of fingolimod ingestion. The present study consisted of a review of cardiovascular data on 180 patients with MS receiving the first dose of fingolimod. The rate of bradycardia in these patients was higher than that observed in clinical trials with very strict inclusion criteria for patients. There were less than $10 \%$ of cases requiring special attention, but no fatal cases. All but one patient continued the treatment after this initial dose. This is the first report on real-life administration of fingolimod to Brazilian patients with MS, and one of the few studies with these characteristics in the world.
\end{abstract}

Keywords: multiple sclerosis, fingolimod, bradycardia, adverse event.

\section{RESUMO}

Fingolimode é um tratamento novo e eficaz para esclerose múltipla (EM). A administração desta droga requer atenção especial para a primeira dose, uma vez que eventos adversos cardiovasculares podem ser observados nas seis horas iniciais da ingestão de fingolimode. 0 presente estudo consistiu de uma revisão de dados cardiovasculares de 180 pacientes com EM ao receberem a primeira dose de fingolimode. A taxa de bradicardia nestes pacientes foi maior do que aquele observada em estudos clínicos que tem critérios de inclusão muito rigorosos para seleção de pacientes. Menos de 10\% dos casos necessitou de atenção especial, mas não houve casos fatais. Todos os pacientes exceto por um continuaram o tratamento após esta dose inicial. Este é o primeiro relato de dados de administração de fingolimode na vida real de pacientes brasileiros com EM, e um dos poucos trabalhos com estas características no mundo.

Palavras-chave: esclerose múltipla, fingolimode, bradicardia, evento adverso.

The efficacy of fingolimod, the innovative oral drug therapy for multiple sclerosis (MS) has been shown in clinical trials and in medical practice ${ }^{1}$. It is widely recommended that, during the first dose of fingolimod, patients should be on an appropriate

\footnotetext{
${ }^{1}$ Departamento de Neurologia, Universidade Metropolitana de Santos, Santos SP, Brazil;

${ }^{2}$ Departamento de Neurologia, Universidade Positivo, Curitiba PR, Brazil;

${ }^{3}$ Departamento de Neurologia, Universidade Federal do Paraná, Curitiba PR, Brazil;

${ }^{4}$ Departamento de Neurologia, Universidade Estadual de Campinas, Campinas SP, Brazil;

${ }^{5}$ Departamento de Neurologia, Universidade Federal de Juiz de Fora, Juiz de Fora MG, Brazil;

${ }^{6}$ Departamento de Neurologia, Hospital de Clínicas de Porto Alegre, Porto Alegre RS, Brazil;

${ }^{7}$ Departamento de Neurologia, Pontifícia Universidade Católica Sorocaba, Sorocaba SP, Brazil;

${ }^{8}$ Clínica Holus MedService, Sao Paulo SP, Brazil;

${ }^{9}$ Departamento de Neurologia, Hospital Beneficência Portuguesa de São Paulo, Sao Paulo SP, Brazil;

${ }^{10}$ Departamento de Neurologia, Centro Hospitalar Unimed, Joinville SC, Brazil;

${ }^{11}$ Departamento de Neurologia, Universidade Federal Fluminense, Niterói RJ, Brazil;

${ }^{12}$ Departamento de Neurologia, Universidade Federal de São Paulo, Sao Paulo SP, Brazil;

${ }^{13}$ Departamento de Neurologia, Hospital de Base do Distrito Federal, Brasília DF, Brazil;

${ }^{14}$ Departamento de Neurologia, Instituto de Neurologia de Curitiba, Curitiba PR, Brazil.

Correspondence: Yara Dadalti Fragoso; Departamento de Neurologia, Universidade Metropolitana de Santos; Rua da Constituição, 374 ; 11015 -470 Santos SP, Brasil; E-mail: yara@bsnet.com.br

Conflict of interest: The pharmaceutical company producing and commercializing fingolimod will only have acess to these data after publication.

Received 31 March 2014; Received in final form 10 May 2014; Accepted 13 June 2014.
} 
medical environment capable to deal with potential cardiovascular complications ${ }^{1,2}$. Transient effects on heart rate are explained by transient agonism of sphingosine-1P receptors in atrial myocytes ${ }^{3}$. As yet, there has been no report on the safety of the first dose of fingolimod in Brazilian patients with MS where the protocol recommends medical observation and cardiovascular monitoring for at least six hours. In fact, except for results on clinical trials with very strict inclusion criteria for patients ${ }^{4}$, there are few reports on the real life experience with the first dose of fingolimod ${ }^{2,5}$.

Retrospective data were collected for 180 patients aged over 18 years diagnosed with MS according to the revised McDonald criteria 6 . These patients were closely monitored during the first dose of fingolimod. Each MS Unit had obtained authorization by the Ethics Committee to proceed with the treatment with fingolimod. Patients were informed that they should contact their doctor in case of any signs or symptoms beyond the observation period (minimum six hours).

Gender, age, cardiac rate and blood pressure were registered for all cases. There were 132 women and 48 men, with an average age of 36.8 years (median=36 years, range $=19$ to 66 years). Five patients had high blood pressure and four patients had right or left branch block before medication. They were kept under observation for longer than six hours and did not develop complications. Two patients had sinus tachycardia and two other patients had sinus bradycardia at the first ECG registration. They did not develop complications. Twelve other patients $(6.7 \%)$ were kept under medical observation for longer than six hours due to symptomatic bradycardia, while three of them (1.7\%) needed to be in intensive care units for developing right branch block or second-degree atrioventricular block. There were no cases of other severe complications and no cases of death among these patients during or after the initial dose, despite the description of possible delayed asystole ${ }^{7}$. At present, $99.4 \%$ of the patients reported here continue the treatment with fingolimod.

Figure shows a summary of data regarding cardiac rate, systolic and diastolic blood pressure up to six hours for all patients. When assessed by one-way ANOVA, the $3^{\text {rd }}$ and $4^{\text {th }}$ hours of observation showed a significant $(\mathrm{P}<0.001)$ lower heart rate than other time points.

Figure also shows the variation in systolic and diastolic blood pressure during the observation period of six hours. There were no isolated cases of marked hypo or hypertension peaks during the whole observation period. When assessed by one-way ANOVA, no significant differences in either systolic or diastolic blood pressure were observed.

The FREEDOMS clinical trial of fingolimod and its extensions showed less than $1 \%$ cases of bradycardia during the first dose ${ }^{8}$. The study of Ontaneda et al. which dealt with clinical practice data also demonstrated $1 \%$ rate of bradycardia as a complication of fingolimod initiation ${ }^{2}$. A recent Italian study reported $2 \%$ cardiovascular adverse events in patients taking the first dose of fingolimod, mainly bradycardia and atrio-ventricular block ${ }^{5}$. The Italian study used a method similar to ours, reporting the results of daily medical practices. For Brazilian patients in the real life series this observation was higher, even though there was a return to normal cardiac rate after a period of up to ten hours in all but three cases.
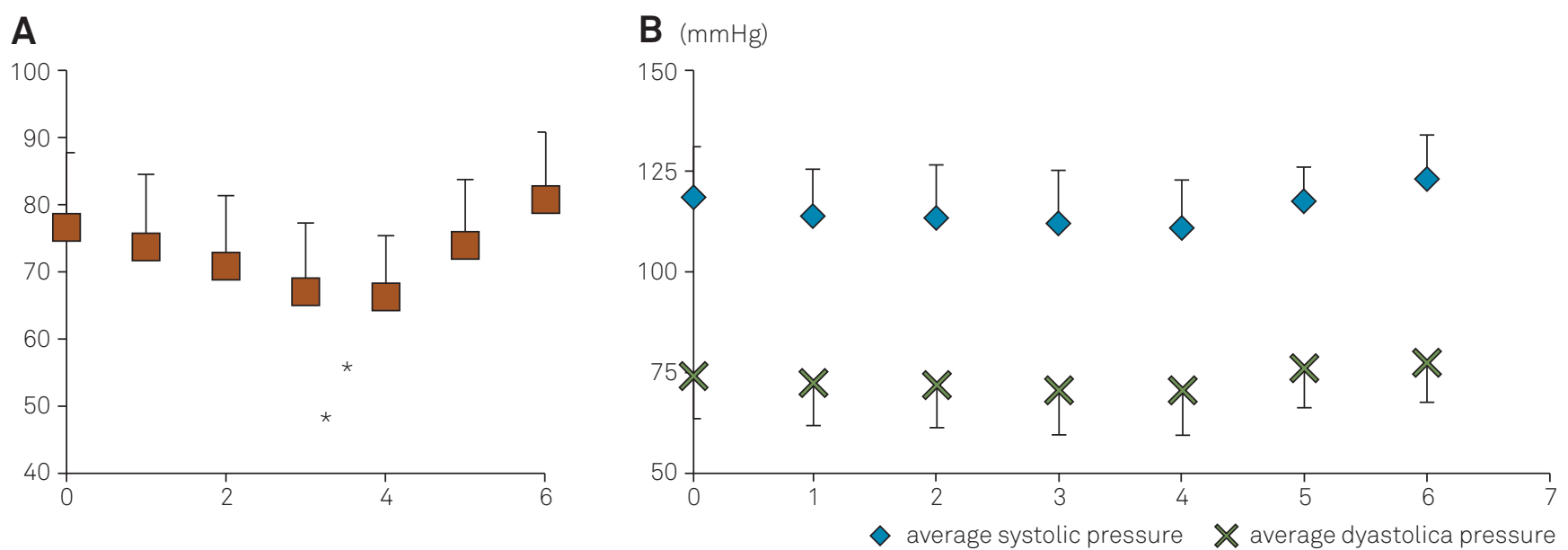

Number of hours of observation (zero=baseline) Heart rate (beats per minute)

Figure. Average values and standard deviation for the heart rate of 180 patients undergoing the first dose of fingolimod. Data registered over six hours of medical observation. ${ }^{*} \mathrm{P}<0.001$ in relation to other time points (A). Average values and standard deviation for the systolic (upper values) and diastolic (lower values) blood pressure of 180 patients undergoing the first dose of fingolimod. Data registered over six hours of medical observation (B). 
It is imperative to register the cardiovascular parameters during the first dose of fingolimod ${ }^{9}$. A much larger retrospective and prospective Brazilian database should be created in order to observe cardiovascular parameters in patients receiving the first dose of fingolimod in our country.

\section{Acknowledgments}

The authors are grateful to all cardiologists who graciously sent data from patients seen at first dose clinical units in Brazil.

\section{References}

1. Thomas K, Ziemssen T. Management of fingolimod in clinical practice. Clin Neurol Neurosurg. 2013;115(Suppl 1):S60-S64.

2. Ontaneda D, Hara-Cleaver C, Rudick RA, Cohen JA, Bermel RA. Early tolerability and safety of fingolimod in clinical practice. J Neurol Sci. 2012;323:167-172.

3. Bünemann M, Liliom K, Brandts BK, et al. A novel membrane receptor with high affinity for lysosphingomyelin and sphingosine 1-phosphate in atrial myocytes. EMBO J. 1996;15:5527-5534.

4. Sanna M, Liao J, Jo E, et al. Sphingosine 1-phosphate (S1P) receptor subtypes S1P1 and S1P3, respectively, regulate lymphocyte recirculation and heart rate. J Biol Chem 2004;279:13839-13848.

5. Laroni A, Brogi D, Morra VB, et al. Safety of the first dose of fingolimod for multiple sclerosis: results of an open-label clinical trial. BMC Neurol 2014;14:65.
6.

Polman CHR, Reingold SC, Banwell B et al. Dianosticcriteria for multiple sclerosis: 2010 Revisions to the Mac Donald criteria. Ann Neurol 2011;69:292-302.

7. Espinosa PS, Berger JR. Delayed fingolimod-associated asystole. Mult Scler 2011;17:1387-1389.

8. Kappos L, Radue EW, O'Connor P, et al. A placebo-controlled trial of oral fingolimod in relapsing multiple sclerosis. N Engl $\mathrm{J}$ Med 2010;362:387-401.

9. Singer BA. Initiating oral fingolimod treatment in patients with multiple sclerosis. Ther Adv Neurol Disord 2013;6:269-275. 